\title{
Ensayos de etnografía teórica. Andes
}

Óscar Muñoz Morán, coordinador

Madrid: Nola Editores

2020, 407 páginas

MARÍA FERNANDA APIPILHUASCO MIRANDA*

Investigadora independiente, doctora en Antropología de El Colegio de Michoacán

DOI: $10.22380 / 2539472 X .2047$

$\Lambda$

ctualmente, los desarrollos académicos sobre lo andino han puesto en debate el carácter general de esta noción, por homogeneizar relativamente la identidad, la historia, la cultura y el pensamiento en Sudamérica. Si bien lo andino alude a una zona geográfica enmarcada en la cordillera de los Andes que abarca parte del territorio boliviano, peruano, chileno, colombiano, venezolano, argentino y ecuatoriano, el grueso de lo que se ha denominado estudios andinistas se concentra en la zona central, que comprende las mesetas elevadas del altiplano y la puna -Argentina, Bolivia, Chile y Perú-. Los estudios antropológicos y sociológicos en dicha zona cobraron relevancia desde mediados de los años setenta; en ellos, los estudiosos se concentraron en las similitudes culturales relacionadas con modos de ser, actuar y pensar prehispánicos, por lo que se asentó la generalización de un pensamiento andino. Sin embargo, aunque las poblaciones de los Andes centrales comparten una historia prehispánica en común, son diversos los procesos históricos coloniales y poscoloniales, las culturas y geografías que constituyen este espacio.

Para Óscar Muñoz, coordinador de Ensayos de etnografía teórica. Andes, el libro del que se ocupa esta reseña, la "búsqueda incansable de un pensamiento andino" (7) está sujeta a escrutinio, pues los Andes y, en concreto, el campo de los Andes centrales es amplio y diverso. Su propuesta es dejar de lado la

mafera.miranda@gmail.com / https://orcid.org/0000-0002-2829-2901 
generalización de una antropología "andinista" para centrarse en etnografías de los Andes que nos brinden guías teóricas para comprender este espacio geográfico construido de manera procesual, relacional y heterogénea, tanto por humanos como por no humanos.

El libro se compone de diez ensayos escritos por Bruce Mannheim, Francisco Pazzarelli, Lucila Bugallo, Denise Y. Arnold, Catherine J. Allen, Daniela Di Salvia, Rosaleen Howard, Óscar Muñoz Morán, Andrew Canessa y Pablo Cruz, cuyo eje central es una reflexión sobre cosmología en los Andes desde el denominado giro ontológico, expuesto principalmente por exponentes como Bruno Latour, Eduardo Viveiros de Castro y Philippe Descola. Este giro funge como punto de partida -incluso desde su crítica- para comprender las relaciones establecidas entre diferentes seres. Con base en dichas etnografías, el compilador nos ofrece tres aspectos teóricos para explicar y comprender los mundos andinos centrales: la relacionalidad, la fluidez y la animacidad común y compartida.

Cada artículo plantea asociaciones particulares, rituales y narrativas, que dan cuenta de la fluidez con la que los diferentes seres parecen constituirse, conectarse, comunicarse y relacionarse. A lo largo del trabajo se nos muestra que el principio relacional implica el flujo y la transformación de una fuerza vital y de la materialidad. Como Allen propone, "todos los seres están intrínsecamente conectados compartiendo una matriz de sustancia mínima” (2020, 17), que hoy en día se ha abordado desde la agencialidad de la materialidad y los objetos. Estas perspectivas parten de lo emic en sus planteamientos y nos sitúan en las discusiones contemporáneas sobre el Antropoceno, las críticas a lo representacional y a un entendimiento privilegiadamente antropocéntrico de la existencia. Aquí, lo no humano constituye lo humano en relación, fluidez y transformación. Con base en lo anterior, la antropología de la fluidez puede ser analizada en otros espacios como una contribución fundamental para el estudio de lo humano y lo no humano en constante construcción, que destaca la diferencia y ambigüedad de las relaciones. Este aspecto coincide con la propuesta de coactividad de Pitrou (2016) en Mesoamérica y con la antropología ecológica de Ingold (2012) —autor clave en la argumentación de los estudiosos que participan en el libro-.

Los trabajos reunidos se centran en el campo boliviano, peruano y argentino, con poblaciones bilingües de habla hispana, quechua y aymara. Si bien la mayoría de los autores trabaja con rituales de paso, alimentación, comensalidad, depredación, crianza, envolturas y almas en comunidades pastoriles y campesinas (Bugallo, Allen, Pazzarelli, Muñoz, Canessa), también hay un estudio que da cuenta de la relación con el turismo y el patrimonio (Cruz). Teóricamente, encontramos posturas basadas en etnografías sobre el papel de la narración oral en lengua quechua que articula la relación entre seres humanos y otros tipos de 
seres (Howard); así como planteamientos que, sustentados en historia, gramática y cognición, postulan una comparación etnográfica y ontológica tanto social como material (Mannheim); o una propuesta físico-ecológica y semiótica que enriquece la teoría animista fenoménica (Di Salvia).

En su generalidad, el libro nos brinda abordajes constructivistas y pragmáticos sobre prácticas de las comunidades en los Andes centrales que buscan dar cuenta de cómo lo humano, en tanto ser, es constituido a través de sus relaciones con otros seres como las montañas, las piedras, los tejidos, los ríos, las osamentas, los muertos, entre otros. Todas estas entidades se categorizan en la jerga ontológica como lo no humano. Con base en ello, Muñoz propone que el mundo andino es relacional (9), lo que implica comprender que lo humano y lo no humano están interrelacionados de diversas formas, niveles, espacios y tiempos para construir el (o los) mundo(s). Estas relaciones configuran asociaciones variadas, duraderas o volátiles.

Los autores examinan la fluidez en las relaciones a partir de las fuerzas anímicas que constituyen a la persona —entidades sociales humanas y no humanas-, concepto que es analizado a la luz de los trabajos de Viveiros de Castro (1998) y Descola (2012). Dichas fuerzas tienen nombres diversos en quechua, aymara y español, como ajayu, kuraji, ánimu, espíritu, alma o camac. En esta compilación, lo novedoso de hablar de una fuerza animada compartida es que se nos presenta acotada en actos particulares que dan cuenta de ella, sin ser una entelequia o un a priori para referirse a lo andino. Esta se expone en los ensayos como prácticas que posibilitan hablar del principio de la ontología relacional en el sentido de animar y contener la fuerza vital, la cual fluye entre humanos, objetos y animales.

En su particularidad, los artículos pueden agruparse de acuerdo con su densidad teórica y etnográfica: el trabajo de Mannheim aporta un marco analítico para abordar las diferencias ontológicas entre las sociedades quechuas antiguas y contemporáneas de una forma sistemática, denominada relatividad ontológica restringida. Siguiendo sus pasos, Di Salvia analiza la cosmología quechua de Ollantaytambo, Cuzco (Perú), mediante una ontología fenoménica del animismo telúrico quechuandino, en la que estudia la noción de la tierra Pachamama desde su heterogeneidad material (físico-ecológica). Con la misma densidad teórica, el trabajo de Howard aporta un análisis de los relatos orales en lengua quechua de los Andes centrales del Perú desde sus aspectos performativos y perspectivistas ontológicos, que funcionan para construir la cosmovisión o entendimiento del mundo de los narradores.

Con mayor énfasis etnográfico, en su trabajo con los pastores quechuas del sur de Jujuy (Argentina), Bugallo muestra las relaciones entre humanos y seres 
poderosos para postular que en la crianza y la depredación entre ellos se establece quiénes son y qué espacios ocupan, lo cual implica influencia mutua. Aquí, la fluidez y el dinamismo son aspectos centrales de las relaciones entre humanos y no humanos. Dichos aspectos también son trabajados por Arnold, quien propone que las prácticas de envolver y desenvolver de los hablantes de aymara hablantes de los Andes sur-centrales de Bolivia son procesos para convertir cosas en personas, con el fin de asegurar la continuidad de la vida. Mediante materiales como las cabezas-trofeo y los textiles, la autora analiza prácticas enfocadas en procesos rituales que transforman objetos en sujetos animados con capacidad de establecer relaciones con otros objetos o entidades.

El concepto de animacidad es fundamental para explicar lo anterior y Allen lo recupera en esta compilación. Basada en su trabajo desde los años ochenta con los quechuas de Songo de Perú, la autora nos ofrece un recorrido teórico y etnográfico sobre el animismo andino y su aportación a la ontología relacional mediante el análisis de las inqaychus andinas. La base del animismo es que los humanos no actúan sobre los objetos, sino que estos son considerados por los sonqueños como sujetos, por lo cual actúan con ellos. Para Allen el mundo andino es construido intrínsecamente en términos de relaciones entre entidades que constantemente se crean las unas a las otras. Entre ellas, las almas, los espíritus o los muertos son cruciales. Al respecto, Pazzarelli plantea que las prácticas de depredación —caza, ingesta, enfermedad, brujería - de los pastores huacheños argentinos que involucran a los animales y a los espíritus están relacionadas con el paisaje, con animales-brujos o animales-animu y con humanos a través de la brujería. Estas prácticas establecen la conexión entre el cuerpo y el alma; además, resultan determinantes para construir la posición de pastores y cazadores en términos de parcialidad.

Por su parte, Muñoz trabaja las relaciones y clasificaciones de los espíritus que conviven con los hablantes de quechua de Coipasi (Bolivia), para mostrar que las almas saqras, habitualmente consideradas como "malas”, están relacionadas con los difuntos que no son recordados. Al registrar los límites entre el recuerdo y el no recuerdo, el autor establece un circuito relacional entre los diversos espíritus y humanos, y propone comprenderlo con base en dos estados: el experimental y el emocional (21). De esta manera, la distinción de los espíritus "malos" y "buenos" resulta estar determinada por la relación entre la vida social y el recuerdo.

En el marco de las relaciones con las almas, el trabajo de Canessa aporta una perspectiva teórica distinta a la del resto de los ensayos por mantener una postura crítica frente al giro ontológico que, para él, corre el riesgo de continuar con el colonialismo. Por ello, propone enfocarnos en el cambio e intercambio 
social a través de la cotidianidad para comprender la agencia atribuida a los seres no humanos. Su trabajo se centra en el estudio del cambio o transformación del pensamiento mediante las prácticas que se ocupan de la entrada y salida del mundo (nacimiento, muerte, etc.) en una comunidad aymara boliviana, mediante las cuales da cuenta de la creación de humanos y su conversión en seres no humanos.

En la línea de adecuación y cambio social, el ensayo de Cruz cierra el libro con un análisis de las comunidades aymaras del sur del Salar de Uyuni (Bolivia). El autor muestra cómo estas poblaciones han incursionado en el turismo y el patrimonio por medio de sus relaciones con las chullpas o ancestros, quienes a partir del repertorio patrimonial se han tornado elementos de cohesión social y recurso económico. Esto implica, para Cruz, una transmutación ontológica que genera cambios categoriales tanto en la fluidez de las temporalidades como en las entidades no humanas.

Sin duda, la totalidad del libro genera una aportación significativa a la antropología y sociología al ampliar las nociones sobre lo social más allá de los humanos, los grupos sociales y la organización. Aquí, lo social se propone como un constructo relacional entre lo humano y lo no humano que da forma a la cosmología y las prácticas. Para todos los que participan en el libro, los actores humanos reconocen una red de relaciones construidas sobre la diferencia que une a lo diferenciado mediante la fluidez de una diversidad de fuerzas anímicas que pasan de un cuerpo a otro, lo que implica que se genere acción social (33). Estas características de lo social no son exclusivas de los Andes centrales; de hecho, el volumen se enmarca en una trilogía en la que se presentan etnografías teóricas en Mesoamérica (Pitarch 2020) y la Amazonía (Calavia 2020), que enriquecen la comprensión etnográfica, teórica y metodológica sobre las comunidades indígenas en América.

Finalmente, la propuesta de pensar los Andes centrales desde sus etnografías y desde la animacidad, la fluidez y la relacionalidad $-\mathrm{y}$ no desde un pensamiento andino generalizado - nos brinda la posibilidad de comprender las relaciones que se construyen en dicho espacio geográfico. Es importante mencionar la necesaria lectura crítica y analítica de este enfoque etnográfico basado en prácticas concretas, pues de lo contrario se corre el peligro de generar fórmulas que encasillen la diversidad de prácticas en un esencialismo no occidental con tendencia a exotizar al otro. En términos de Abercrombie (2016) y Canessa, la apuesta no radica en plantear a las cosmologías andinas como algo "opaco, exótico e inconmensurable con la racionalidad europea” (Canessa 2020, 341), sino en mostrar que investir de intencionalidad o agencia a las cosas es una 
manifestación generalizada de prácticas semióticas humanas (Abercrombie 2016, 3). Es decir, todas las culturas somos animistas porque atribuimos capacidad de acción a los no humanos mediante actos comunicativos; por ello lo central no es encontrar un tipo de alteridad radical — “modernos”/“indígenas”-, sino establecer lo que nos hace semejantes y las diversas formas en que se construyen los mundos.

\section{Referencias}

Abercrombie, Thomas A. 2016. "The iterated mountain: things as signs in Potosí". Journal of Latin American And Caribbean Anthropology 21 (1): 83-108. https://doi.org/10.1111/ jlca.12184

Allen, Catherine. 2020. "Inqaychus andinas y la animacidad de las piedras". En Ensayos de etnografía teórica. Andes, coordinado por Óscar Muñoz Morán, 196-226 Madrid: Nola Editores.

Calavia, Óscar, coord. 2020. Ensayos de etnografía teórica. Tierras bajas de América del Sur. Madrid: Nola Editores. https://doi.org/10.37552/eet.tbas

Canessa, Andrew. 2020. "Un carrusel de cosmologías: giros ontológicos en el mundo andino". En Ensayos de etnografía teórica. Andes, coordinado por Óscar Muñoz Morán, 341-364. Madrid: Nola Editores.

Descola, Philippe. 2012. Más allá de naturaleza y cultura. Buenos Aires: Amorrortu Editores.

Ingold, Tim. 2012. "Toward an ecology of materials”. Annual Review of Anthropology 41 (1): 427-442. https://doi.org/10.1146/annurev-anthro-081309-145920

Pitarch, Pedro, coord. 2020. Ensayos de etnografía teórica. Mesoamérica. Madrid: Nola Editores. https://doi.org/10.37552/eet.mesoam

Pitrou, Perig. 2016. “Co-activity in Mesoamerica and in the Andes”. Journal of Anthropological Research 72 (4): 465-482. https://doi.org/10.1086/689295

Viveiros de Castro, Eduardo. 1998. "Cosmological deixis and Amerindian perspectivism". The Journal of the Royal Anthropological Institute 4 (3): 469-488. https://doi. $\operatorname{org} / 10.2307 / 3034157$ 